\title{
Potential Cislunar and Interplanetary Proving Ground Excursion Trajectory Concepts
}

\author{
Melissa L. McGuire \\ Laura M. Burke \\ Kurt J. Hack \\ NASA Glenn Research Center \\ 21000 Brookpark Road. \\ Cleveland, Oh 44135 \\ Melissa.L.McGuire@nasa.gov \\ Laura.M.Burke@nasa.gov \\ Kurt.J.Hack@nasa.gov
}

\author{
Nathan J. Strange \\ Timothy P. McElrath \\ Damon F. Landau \\ Gregory Lantoine \\ Jet Propulsion Laboratory \\ 4800 Oak Grove Dr. \\ Pasadena, CA 91109 \\ Nathan.J.Strange@jpl.nasa.gov \\ Timothy.P.McElrath@jpl.nasa.gov \\ Damon.Landau@jpl.nasa.gov \\ Gregory.Lantoine@jpl.nasa.gov
}

\author{
Pedro Lopez \\ Mark A. McDonald \\ NASA Johnson Space Center \\ 2101 NASA Road 1 \\ Houston, TX 77058 \\ Pedro.Lopez-1@nasa.gov \\ Mark.A.McDonald-1@nasa.gov
}

\begin{abstract}
NASA has been investigating potential translunar excursion concepts to take place in the 2020 s that would be used to test and demonstrate long duration life support and other systems needed for eventual Mars missions in the 2030s. These potential trajectory concepts could be conducted in the proving ground, a region of cislunar and near-Earth interplanetary space where international space agencies could cooperate to develop the technologies needed for interplanetary spaceflight. Enabled by high power Solar Electric Propulsion (SEP) technologies, the excursion trajectory concepts studied are grouped into three classes of increasing distance from the Earth and increaseing technical difficulty: the first class of excursion trajectory concepts would represent a 90-120 day round trip trajectory with abort to Earth options throughout the entire length, the second class would be a 180-210 day round trip trajectory with periods in which aborts would not be available, and the third would be a 300-400 day round trip trajectory without aborts for most of the length of the trip. This paper provides a top-level summary of the trajectory and mission design of representative example missions of these three classes of excursion trajectory concepts.
\end{abstract}

\section{TABLE OF CONTENTS}

1. INTRODUCTION . .1

2. PROVING GROUND BACKGROUND...........................2

3. ENABLING TECHNOLOGY ASSUMPTIONS..............2

4. EXCURSION MISSION CONCEPT SUMMARY ...........2 5. EXCURSION CONCEPT TRAJECTORY ASSUMPTIONS. 3

6. 90-120 DAY CLASS EXCURSION CONCEPTS (TYPE 1) 4

7. 180-210 DAY CLASS EXCURSION CONCEPTS (TYPE 2) . .6

8. 300 - 400 DAY CLASS EXCURSION CONCEPTS

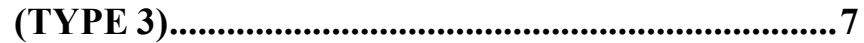

9. SUMMARY AND CONCLUSIONS............................8 ACKNOWLEDGEMENTS..........................................8

REFERENCES .........................................................9

BIOGRAPHY . .9

\section{INTRODUCTION}

One of the goals of the National Aeronautics and Space Administration (NASA), as outlined in the NASA Authorization Act of 2010, has been to develop the ability to send humans to Mars in the 2030s. These goals are outlined in the NASA Authorization Act of 2010 and in the 2010 U.S. National Space Policy. To enable these missions, NASA is working on defining a plan to develop and prove out the capabilities and technologies through missions in a "Proving Ground", set to take place in the 2020s. The Future Capabilities Mission Design team has investigated a variety of "translunar excursion trajectory" concepts as part of this multi-phase plan, that could be used to test increasing deep space habitat capabilities with the goal of demonstrating those capabilities needed for a Mars or Mars moon mission by the end of the Proving Ground campaign. The Proving Ground as notionally depicted in Figure 1, is the name given to both the area of cislunar space farther than Low Earth Orbit (LEO) but not yet as far as Mars, and to the set of proving missions designed to test out deep space technologies and capabilities. These concepts would use this near earth "Proving Ground" to demonstrate the technologies and operations directly applicable to future human Mars missions.

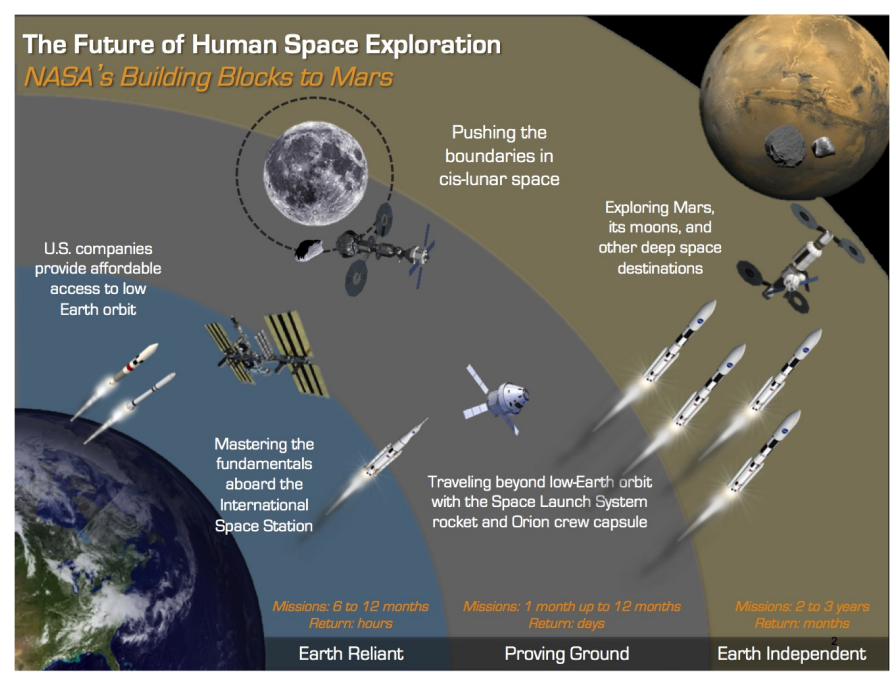

Figure 1. Multi-Phase Approach to Human Exploration 


\section{of Mars}

\section{Proving Ground Background}

The National Aeronautics and Space Administration (NASA) is currently developing the concepts and capabilities needed to send humans to perform missions to Mars in the 2030s. Under the Human Architecture Team (HAT) a multi-phase development plan, both of technology and operational capabilities called the Evolvable Mars Campaign (EMC) is evaluating what it takes to go to Mars. As a stepping-stone to this ultimate capability, a series of missions classified as the Proving Ground are also under study. The proving ground identifies both an area of space farther out than Low Earth Orbit (LEO), but not as far as Mars, and also identified the timeline during which these conceptual missions would occur. They are notionally set to occur before the eventual Mars surface missions. The goal of this Proving Ground is to incrementatlly develop the knowledge and confidence to carry out a multi-year human mission to Mars.

\section{EnABling Technology Assumptions}

The minimal flight elements assumed for these excursion concepts are the Space Launch System (SLS), Orion, cislunar transit habitat module(s), and a 150-kW-class Solar Electric Propulsion (SEP) stage. Some individual trajectory concepts could use an in-space crew taxi vehicle such as an international partner's lunar ascent module, if available. The SLS, Orion, and Solar Electric Propulsion in-space propulsion stage were assumed as an integral part of the proving ground mission concepts. The SLS, combined with Orion, deliver crew and architecture elements to space. The Orion is responsible for returning the crew from space back to Earth. SEP propels the integrated Cislunar Transit Habitat stack on excursions beyond cislunar space.

\section{Multi-Purpose Crew Vehicle (Orion)}

Use of the Orion to carry four crewmembers was included in all three excursion class concepts, but the Orion is not assumed to flow with the stack to the final destination for the third class of excursions. The Orion consists of a crew module (CM), service module (SM), launch abort system (LAS), spacecraft adapter (SA), and SA-jettisoned fairing panels. The Orion, as assumed in this analysis is sized for 4 crewmembers with a maximum standalone duration of 21 days, which includes 3 days for contingencies. The mission duration limitation is driven by the consumables available on Orion. A longer overall mission duration is possible if Orion were, during some or all of its flight, attached to an external source (e.g., habitat module, logistics module) from which it could draw consumables. For the trajectory analyses presented in this paper, a total wet mass of 25t (all units are assumed to be metric throughout this study and as reported in this paper) was assumed for the Orion as part of the payload stack to be propelled during these excursion trajectories by the SEP stage.
Space Launch System (SLS)

For the Proving Ground concepts, it was assumed that the SLS, in its Block 1B configuration, delivered all of the excursion assets to cislunar space. The SEP stage was not assumed to spiral from a low earth orbit (LEO) and deposit itself or its payload in the final lunar starting orbits. The SLS Block 1B includes an Exploration Upper Stage (EUS) that is assumed to provide the performance required to transport the Orion along with a co-manifested payload, or dedicated payloads (cargo configuration) to cislunar space. For study purposes, the following fundamental post-Trans Lunar Injection (TLI) performance parameters are assumed: payload delivery capacity of $42,500 \mathrm{~kg}$; maximum achievable C3 of $-1 \mathrm{~km}^{2} / \mathrm{s}^{2}$; and inclination of $28.5^{\circ}$. No additional analysis of the launch to orbit trajectory was performed.

\section{Cislunar Transit Habitat System}

For the proving ground, it was assumed that the SEP stage will transfer the cislunar transit habitat both with and without the crew on board. The excursion trajectories described in this report take place with the crew docked and on-board the habitat. For the trajectory analysis, the total mass of the cislunar transit habitat was assumed to be 50t. This mass includes the 40t assumed mass of the habitat, crew and all consumables and 10t of margin mass. This margin mass allows for freedom of future design of the habitat. Throughout this paper, the Cislunar Transit Habitat is also referred to as Habitat for convenience.

\section{SEP TDM (Heritage) Technologies}

The excursion trajectories presented in this paper all assumed the use of high power Solar Electric Propulsion (SEP) as primary propulsion. The SEP vehicle used in these concepts is assumed to be an in-space propulsion system capable of transiting a crewed cislunar transit habitat on each of the excursions and performing repositioning maneuvers in between transits with the crew. The $150 \mathrm{~kW}$ SEP stage assumed in this analysis is based on the technology proposed for the Asteroid Redirect Robotic Mission [1] which aims to retrieve a large boulder from an asteroid and place it in orbit of the Moon where it would be visited by astronauts as a precursor to human interplanetary missions. Referred to in previous analysis as the ARRM Block 1a, this notional SEP stage assumed a power of 150 $\mathrm{kW}$ to the thruster system, $190 \mathrm{~kW}$ EOL (End of Life) at 1 AU Solar Arrays, a total Xe (Xenon) capacity of 16t, and a dry mass of $\sim 8 \mathrm{t}$. [2]

\section{EXCURSION CONCEPT SUMMARY}

\section{Excursion Concept Categories}

As previously mentioned, the Future Capabilities Mission Design team has been assessing potential candidates for excursion trajectories to take place nominally during the Proving Ground. The excursion concepts are differentiated and grouped into three classes or types based on increasing 
mission complexity and distance from Earth as listed in Table 1. In order to reduce confusion, these trajectories will be referred to as Type 1, 2, and 3 throughout the report: Type 1 trajectories have a crew duration of 90-120 days and robust Orion abort to Earth options throughout; Type 2 trajectories are 180-210 days in duration and may have blackout periods when Orion aborts are not available; and Type 3 trajectories are 300-400 days in duration and do not assume Orion aborts for most of the transit. When the Type 2 and Type 3 trajectories do not have Orion aborts available, they may have abort options using the SEP stage and the habitat module, but these would in general be longer flight time than the Orion aborts. Notionally, any or all of these excursion missions could take place in the latter half of the 2020 s but no assumption has been made as to the dates or sequence of these excursions. All dates assumed were done so for trajectory calculations.

Table 1. Example Excursion Categories

\begin{tabular}{|c|c|}
\hline Excursion Mission Type & $\begin{array}{c}\text { Duration } \\
\text { (days) }\end{array}$ \\
\hline \hline Excursion Trajectory Type 1 & $90-120$ \\
\hline Excursion Trajectory Type 2 & $180-210$ \\
\hline Excursion Trajectory Type 3 & $300-400$ \\
\hline
\end{tabular}

\section{Excursion Concept Trade Space}

At the time of this paper, ten potential excursion destination concepts have been identified for further study. These concepts were feasible trajectories that the assumed SEP stage would be capable of flying. More concepts will be added in time. Of those ten, one to two in each trajectory duration category have been examined in more detail and are captured in this paper.

The excursion trajectory concepts identified so far are:

- $\quad$ Type 1 (90-120 days)

- Asteroid Redirect Crew Mission (ARCM) currently under study as part of the ARRM

○ High-Energy Lunar trajectories \& hyperbolic rendezvous demonstration

- Cislunar SEP transfer

- Asteroid intercept (i.e. fast asteroid flyby trajectorty)

- $\quad$ Type 2 (180-210 days)

○ Earth-Sun L2 / JWST (James Web Space Telescope) rendezvous

○ High-Energy Lunar trajectories \& hyperbolic rendezvous demonstration

- Cislunar SEP transfer

- Comet intercept trajectory (i.e. fast comet flyby)

- $\quad$ Type 3 (300-400 days)

○ Earth Resonant Orbit
○ 2000 SG344 Asteroid Rendezvous and Landing

\section{EXCURSION CONCEPT TRAJECTORY AsSumptions}

The translunar excursion concepts were nominally envisioned as as three trajectories, being flown using the same Solar Electric Propulsion (SEP) vehicle as the in-space transportation stage without refueling needed. Whether they occurred sequentially is unimportant to the trajectory analysis performed. The limiting factor is the amount of Xe capacity assumed in the SEP stage. As long as the total propellant load of the three trajectories was within the Xe capacity, there would be no requirement for refueling. These excursion trajectories fall into three categories, each of longer duration and greater distances from the Earth than the previous mission.

\section{Excursion Vehicle Assumptions}

The Excursion Vehicle is comprised of the SEP stage and the human payload. For excursion trajectories of Type 1 and Type 2, the human payload portion of the vehicle is a cislunar habitat and the Orion Spacecraft. For the third excursion trajectory, Type 3 , the payload portion of the vehicle is the cislunar habitat. The assumed masses for these components are captured in table 2 below.

Table 2. Excursion Concept Payload Vehicle Assumptions

\begin{tabular}{|c|c|}
\hline Payload Element & Mass (t) \\
\hline \hline Cislunar Habitat & 40 \\
\hline Cislunar Habitat Margin & 10 \\
\hline Orion Spacecraft & 25 \\
\hline
\end{tabular}

\section{SEP Vehicle Assumptions}

The assumed capabilities of the SEP system used in the trajectory analysis are captured in table 3.

Table 3. SEP Vehicle Assumptions

\begin{tabular}{|l|l|l|}
\hline \multicolumn{1}{|c|}{$\begin{array}{c}\text { SEP System } \\
\text { Assumptions }\end{array}$} & \multicolumn{1}{c|}{ Value } & \multicolumn{1}{c|}{ Details } \\
\hline \hline EP system power & $\sim 150 \mathrm{~kW}$ & $12+0(13.3 \mathrm{~kW}$ thrusters $)$ \\
\hline $\begin{array}{l}\text { Spacecraft power } \\
\text { EOL, 1AU }\end{array}$ & $\sim 190 \mathrm{~kW}$ & $\begin{array}{l}\text { EOL, assumes margin and } \\
\text { array degradation }\end{array}$ \\
\hline $\begin{array}{l}\text { Thruster Duty } \\
\text { Cycle }\end{array}$ & $90 \%$ & $\begin{array}{l}\text { Allow for missed thrust, } \\
\text { operations while coasting }\end{array}$ \\
\hline Power loads & $20 \mathrm{~kW}$ & $\begin{array}{l}\text { For Spacecraft housekeeping, } \\
\text { and cislunar Habitat loads }\end{array}$ \\
\hline $\begin{array}{l}\text { Xe Propellant } \\
\text { Capacity }\end{array}$ & $16 \mathrm{t}$ & $\begin{array}{l}\text { Total propellant capability of } \\
\text { the ARV Block 1a SEP Stage }\end{array}$ \\
\hline $\begin{array}{l}\text { SEP stage dry } \\
\text { mass }\end{array}$ & $8 \mathrm{t}$ & $\begin{array}{l}\text { Assumption of the dry mass } \\
\text { with growth of a 150 kW }\end{array}$ \\
\hline
\end{tabular}




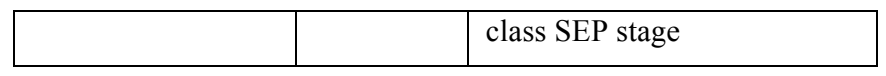

\section{Electric Thruster Assumptions}

The EP thrusters used in the $150 \mathrm{~kW}$ SEP stage modeled in these excursion trajectories are assumed to be the same as those being developed for the ARM (Asteroid Redirect Mission) ARV (Asteroid Redirect Vehicle). [5] The thruster performance curves used for this analysis are the same as those used in the planning stages for the ARM trajectory design. For the ARRM thrusters, several modes of thrust are currently under study. In referring to the performance of the electric thrusters, terminology is used to differentiate between the thrust levels of the same thruster operating at differring specific impulses (Isp). For the analysis presented in this paper, some of the missions were assessed assuming a "High Isp Mode" (low thrust levels, Isp $3000 \mathrm{sec}$ ) where transfer time was not as crucial as propellant mass, while others used an assumption of a "High Thrust Mode" (relatively higher thrust levels for this thruster operating at an Isp $2000 \mathrm{sec}$ ) in order to optimize the mission duration.

\section{90-120 Day Class EXCURSION CONCEPTS (TYPE 1)}

\section{Type 1 Class Concept Summary}

The Type 1 class concepts focused on those that could be conducted in 90-120 days and ensure the ability for Orion to abort back to Earth at any time during the mission. The Orion's propellant capacity limits the amount of delta $\mathrm{V}$ it is capable of imparting and therefore limits the orbits from which it can return to the Earth. Given this constraint, these trajectory concepts all focused on operations done within and around cislunar space. For all of the potential Type 1 candidates, it was assumed that the SEP stage is responsible for the propulsive transfer of the 50t habitat to line up for the crew's arrival, and then of the entire stack including the $25 \mathrm{t}$ Orion after it docks with the SEP/Habitat. When the crew is on board and the Orion is docked, the stack would consist of the SEP stage (8t), the habitat module with the crew (50t) and the Orion docked (25t) for a total mass of $83 \mathrm{t}$ pushed by the SEP stage. The crew will use Orion to arrive at and depart from the SEP/Habitat spacecraft stack and the SEP stage will push around both the habitat and the Orion during crew operations. Nominally, the SEP/Habitat stack starts in a NRO (Near Rectilinear Orbit) about the moon and then transits to the orbits of interest. This choice of starting orbit is still under investigation. Table 4 lists the Type 1 mission concepts identified during the initial brainstorming sessions. Of these, three are presented in more detail in this section.

Table 4. Excursion Type 1 Examples

\begin{tabular}{|l|l|}
\hline \multicolumn{1}{|c|}{ Mission Name/Target } & \multicolumn{1}{|c|}{ Description } \\
\hline \hline $\begin{array}{l}\text { Asteroid Redirect Crew } \\
\text { Mission (ARCM) }\end{array}$ & $\begin{array}{l}\text { The already planned crew phase of } \\
\text { the Asteroid Redirect Mission } \\
\text { (ARM) could be extended to 90 }\end{array}$ \\
\hline
\end{tabular}

\begin{tabular}{|l|l|}
\hline \hline & $\begin{array}{l}\text { days if a habitat module is added to } \\
\text { the ARCM. }\end{array}$ \\
\hline $\begin{array}{l}\text { High-Energy Lunar } \\
\text { trajectories \& hyperbolic } \\
\text { rendezvous } \\
\text { demonstration. }\end{array}$ & $\begin{array}{l}\text { A Lunar gravity-assist tour. This } \\
\text { trajectory would begin with the } \\
\text { demonstration of a hyperbolic } \\
\text { rendezvous of Orion with the } \\
\text { Habitat. An example 90-day Lunar } \\
\text { cycler trajectory with 6 Lunar } \\
\text { flybys and three backflip orbits } \\
\text { over the Lunar poles has been } \\
\text { developed. }\end{array}$ \\
\hline Cislunar SEP transfer & $\begin{array}{l}\text { The crew would ride along with the } \\
\text { habitat during all or part of a } \\
\text { cislunar SEP transfer. An example } \\
\text { trajectory of a DRO to NRO } \\
\text { transfer has been studied. }\end{array}$ \\
\hline Asteroid Intercept & $\begin{array}{l}\text { A fast flyby of an asteroid that } \\
\text { naturally passes close to the Earth. } \\
\text { An example trajectory to asteroid } \\
1999 \text { AN10 in 2027 has been } \\
\text { developed. }\end{array}$ \\
\hline
\end{tabular}

\section{High Energy Lunar Transfer Option}

High-Energy Lunar trajectories have a higher energy in the Circular Restricted Three Body Problem (CR3BP) than orbits like the DRO (Distant Retrograde Orbit) or NRO and have a positive $\mathrm{V}$-infinity $\left(\mathrm{V}_{\infty}\right)$ with respect to the Moon. These orbits consist of a sequence of resonant, nonresonant, or backflip Moon-Moon transfers with Lunar Gravity Assists (LGAs) in-between. They can be quickly entered with low $\Delta \mathrm{V}$ (Delta-V) both from interplanetary transfers and low-perigee orbits (i.e. launch trajectories). Low-energy lunar trajectories such as the NRO and DRO can be reached from high-energy trajectories for very low $\Delta \mathrm{V}$ with 3-6 month transfers or from quick transfers with relatively high $\Delta \mathrm{V}(100-400 \mathrm{~m} / \mathrm{s})$.

Figure 2 shows an example High-Energy Lunar transfer that alternates between a 24-day non-resonant transfer and 14 day backflips plotted in the Earth-Moon rotating frame, for a total cycle time of 38 days. In this example, the backflip trajectories alternate between Northern and Southern, but similar trajectories exist that do not alternate. This trajectory is ballistic in the CR3BP and can repeat indefinitely. In the full force model, it is expected that it could be maintained for very low $\Delta \mathrm{V}(<\sim 10 \mathrm{~m} / \mathrm{s} /$ year $)$, but that analysis is not yet completed. 


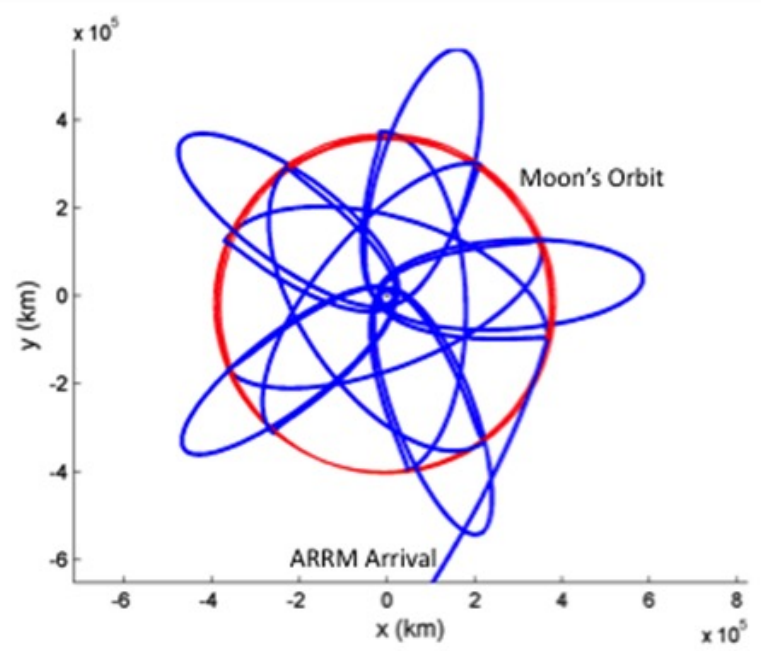

Figure 2. 48-Day High-Energy Lunar Trajectory Example in the Earth-Moon Rotating Frame

Figure 3 shows this trajectory as displayed in an inertial frame. This trajectory is propagated in the full force model for 5 cycles ( 8 months) and requires no deterministic DeltaV. This example trajectory also connects up to an ARRM interplanetary transfer. Currently, ARRM is targetting a DRO (Distant Retrograde Orbit) about the moon for its final orbit. It is in this orbit that the asteroid is currently assumed to be stored for the long term, and to this orbit that the Orion will join with the ARV and asteroid to carry out the crew portion of the mission. However, additional analysis is ongoing to evaluate the optimal final orbit placement for the asteroid from both an Orion and a stability perspective. For ARRM, because of the lower $\Delta \mathrm{V}$ requirements on the return insertion at Earth, high-energy lunar trajectories offer the potential for either a larger boulder return mass or a later launch date.

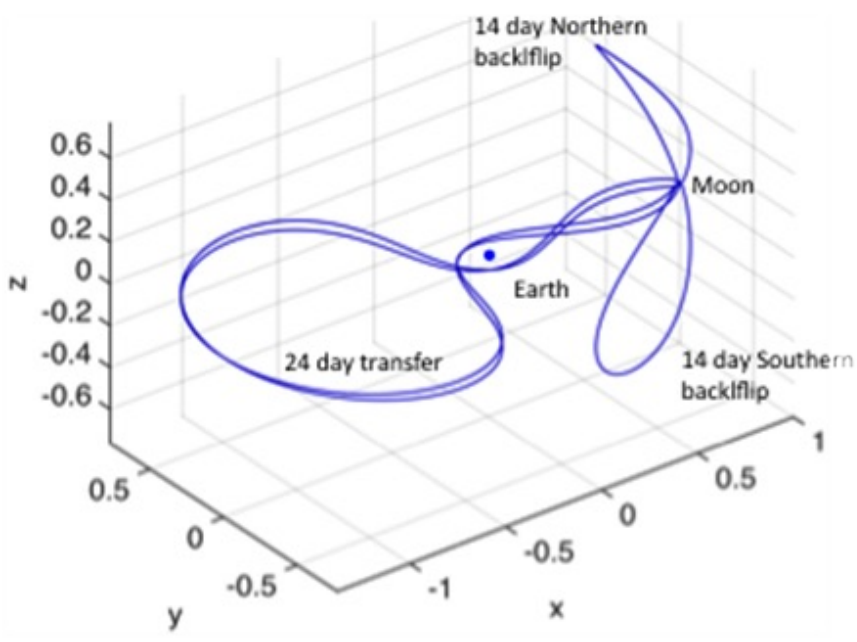

Figure 3. Five Cycles of 48-Day High-Energy Lunar Trajectory Example (Inertial Frame)

\section{Cislunar SEP Transfer Option}

This option for a Type 1 class mission would have the crew fly in a habitat module while it is being transitioned between two cislunar orbits by a SEP stage. The stack would consist of the SEP stage (8t), the habitat module with the crew (50t) and the Orion docked (25t) for a total mass of $83 t$ pushed by the SEP stage. Figure 4 shows an example 90 day SEP transfer from a Lunar DRO to an NRO using a $150 \mathrm{~kW}$ SEP stage.

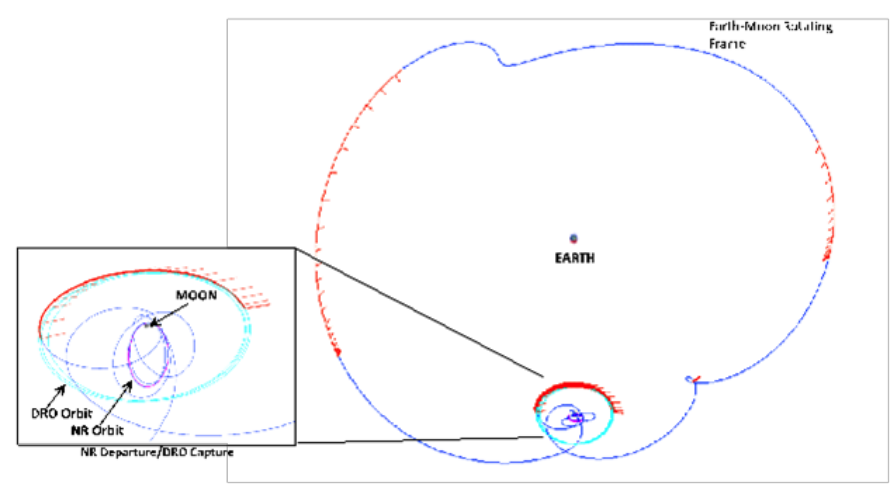

Figure 4: Lunar DRO to NRO low thrust transfer

\section{Asteroid Intercept Option}

Occasionally an asteroid will pass through the Earth-Moon System at around the lunar radius or lower. When this happens, an Type 1 High Energy trajectory can be used to fly by that asteroid. This option for Type 1 would demonstrate precise, time-critical deep space navigation of a human spacecraft. Table 5 list some candidate asteroids with well determined orbits that pass within the Moon's orbit between 2025 and 2030. [3]

Table 5: Candidate Asteroid Intercept Targets

\begin{tabular}{lll}
\hline Target & Earth Close Approach & Diameter est. \\
\hline 1999 AN10 & 2027-Aug-7 & $700-2470 \mathrm{~m}$ \\
2001 WN5 & 2028-Jun-26 & $580-2060 \mathrm{~m}$ \\
Apophis & 2029-Apr-13 & $325 \mathrm{~m}$ \\
2001 AV43 & 2029-Nov-11 & $30-110 \mathrm{~m}$ \\
\hline
\end{tabular}

An example Type 1 class asteroid intercept trajectory is shown in Figure 5 below. The SEP stage is responsible for positioning the habitat stack for docking with Orion. The Orion is launched on an SLS and meets up wih the $\mathrm{SEP} /$ Habitat stack. Once attached, the SEP stage is responsible for maneuvering the entire SEP plus habitat plus Orion stack as shown on the blue trajectory line. The red line in the figure represents the path that the asteroid will take as it makes its closest approach to Earth. This intercept for asteroid 1999 AN10 takes place in 2027 when the asteroid makes its Earth close approach. Should this date not work for the Proving Ground missions, alternate candidate asteroids would provide the same sort of flyby mission and 
viewing opportunity. A conceptual view of the habitat/SEP stack as the asteroid approaches is shown in Figure 6.

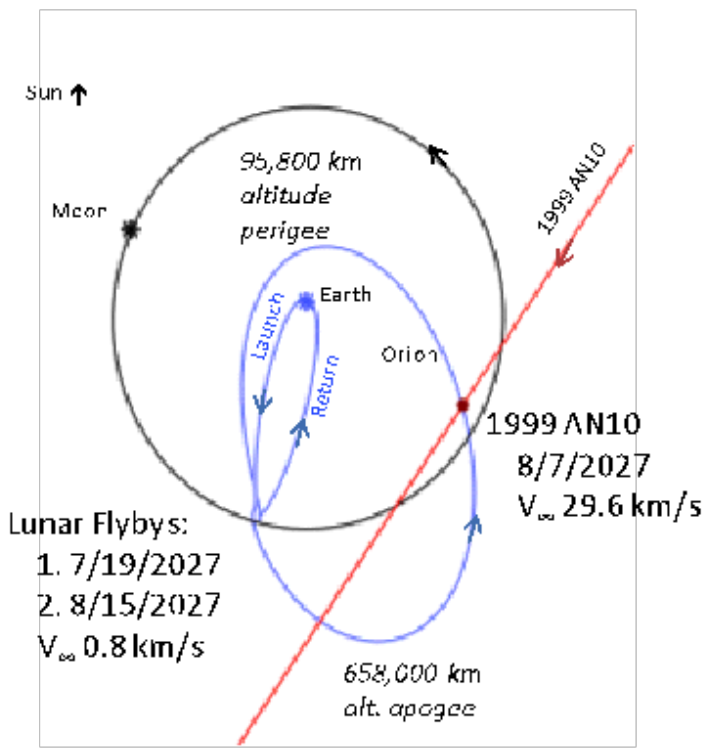

Figure 5: Conceptual Type 1 Asteroid Intercept trajectory

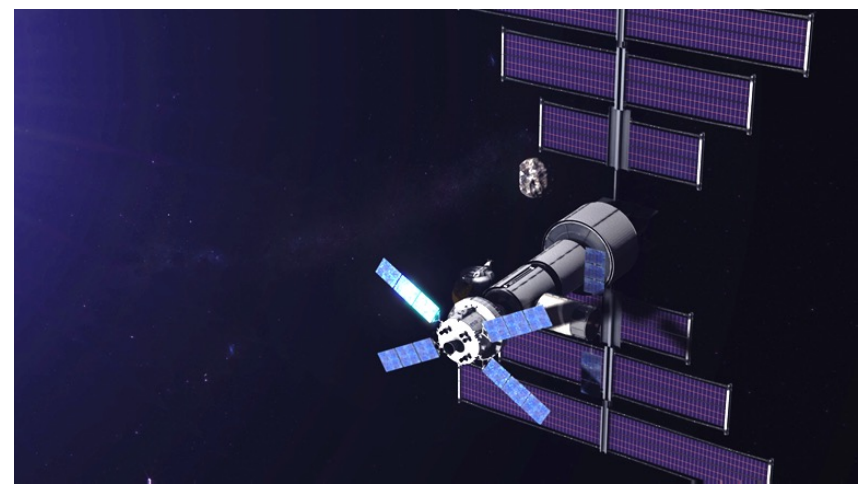

Figure 6: Conceptual View of Cislunar Stack as Asteroid 1999 AN10 Approaches

\section{180-210 DAY Class EXCURSION CONCEPTS (TYPE 2)}

\section{Type 2 Class Options Summary}

The second of the excursion Type concepts is a 180-day round trip class mission with partial Orion abort coverage. For these excursion concepts, the Orion will be included in the mass of payload stack pushed by the SEP stage (50t habitat plus $25 \mathrm{t}$ Orion), but will only provide abort capability for as long as it is in range to do so. It is assumed that the stack departs from and returns to a NRO. The SEP stage is responsible from moving the Cislunar Habitat and Orion stack from a NRO staging orbit and returning it back to this same orbit. Several different excursion options have been identified that would be possible within the 180 day range and are presented in Table 6 . This class of excursion options (180-210 days) include a round-trip low-thrust mission to a Sun-Earth Lagrange point 2 (SEL2), an Earth backflip orbit that would get $\sim 16$ Lunar distances out of the ecliptic, and a flyby of a comet such as 249P/Linear. The intention of the Type 2 class of missions is to continue the demonstration of extended deep space mission operations to longer times and further distances than those of the Type 1 class excursion concepts. Of these, the JWST (SEL2) concept is presented in more detail.

Table 6. Excursion Type 2 Examples

\begin{tabular}{|l|l|}
\hline \multicolumn{1}{|c|}{$\begin{array}{c}\text { Mission } \\
\text { Name/Target }\end{array}$} & \multicolumn{1}{|c|}{ Description } \\
\hline \hline Sun Earth L2 & $\begin{array}{l}\text { This trajectory would visit the James } \\
\text { Webb Space Telescope in its orbit about } \\
\text { the Sun-Earth LaGrange point 2 (SEL2) }\end{array}$ \\
\hline $\begin{array}{l}\text { Out of the Ecliptic } \\
\text { missions }\end{array}$ & $\begin{array}{l}\text { The SEP vehicle would perform an Earth } \\
\text { backflip starting from the Earth NRO to } \\
\text { move the orbit of the spacecraft several } \\
\text { degrees in inclination out of the ecliptic } \\
\text { plane. }\end{array}$ \\
\hline Comet intercept & $\begin{array}{l}\text { This trajectory is similar to the asteroid } \\
\text { intercept, in that it intercepts the comet } \\
\text { 249/LINEAR orbit. Starting from a lunar } \\
\text { orbit (NRO, or DRO is TBD), the SEP } \\
\text { spacecraft will travel to an intercept } \\
\text { position of a comet and return to orbit } \\
\text { about the moon. }\end{array}$ \\
\hline
\end{tabular}

\section{JWST Round Trip Trajectory Concept Summary}

The Type 2 trajectory concept examined in more detail and presented here is a round trip to the orbit of the James Webb Space Telescope (JWST). Because the JWST is located in the Sun-Earth L2 point, the launch dates can change and result in essentially the same round trip trajectory. The trajectory analysis for this trajectory assumed the SEP/habitat stack departs from an NRO and thrusts toward the JWST orbit. The total transfer time of the round trip mission is $\sim 196$ days, with 66 days spent in the vicinity of the JWST. The $150 \mathrm{~kW}$ EP system is assumed to be operating in a high thrust mode (Isp $2000 \mathrm{sec}$ ) at a 90\% duty cycle to allow for margin and missed thrust.

Shown in Figure 7 below, the $150 \mathrm{~kW}$ SEP stage with the Habitat and crewed Orion stack begins the outbound transit from an NRO orbit about the moon. The outbound leg of the trajectory starts with 3.4 days thrusting to impart a small delta $\mathrm{V}$ of $23.2 \mathrm{~m} / \mathrm{s}$. The initial thrusting is followed by a 35.4 day coast leg and then a 36.6 day thrust arc imparting the final $253.2 \mathrm{~m} / \mathrm{s}$ delta $\mathrm{V}$ to arrive at the JWST halo orbit about the SEL2. After spending 66 days at JWST, the SEP stage performs a $116.6 \mathrm{~m} / \mathrm{s}$ delta $\mathrm{V}$ thrust maneuver of 16.7 days, followed by 33.6 days of coasting. After 4.7 days of thrusting to perform a delta $\mathrm{V}$ of $33.1 \mathrm{~m} / \mathrm{s}$, the SEP stage and habitat stack, with the Orion, returns to the NRO about the moon. From here the Orion leaves the SEP/Habitat stack to return the crew to the earth. 


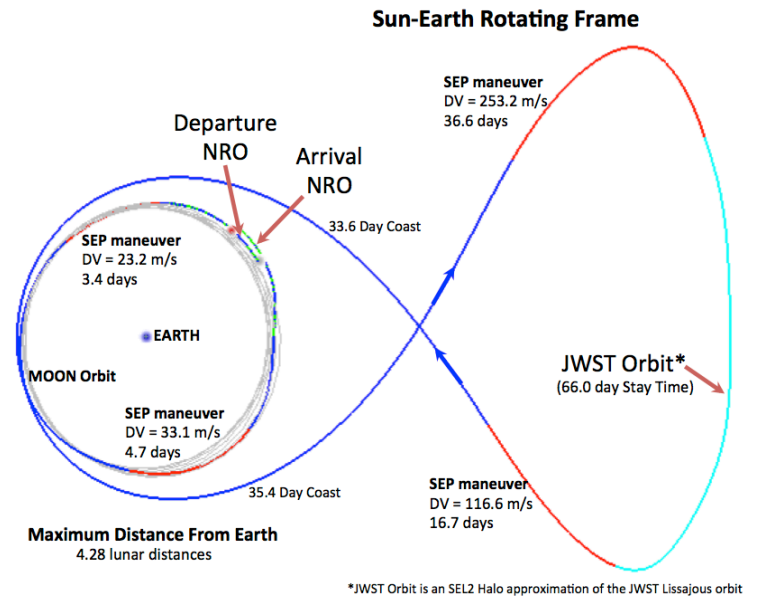

Figure 7: Conceptual TYPE 2 round trip mission to JWST

\section{300 - 400 DAY ClaSS EXCURSION CONCEPTS (TYPE 3)}

\section{Type 3 Class Mission Concept Summary}

The third of the potential excursion concept types is a 300400 day round trip class trajectory. For this excursion concept, it is assumed that the Orion will no longer be included in the payload stack pushed by the SEP stage on the round trip excursion. Instead, an Orion will be launched on an SLS to deliver the crew to the stack and return to Earth (uncrewed) before departure, and a separate Orion will be launched to lunar orbit to retrieve the crew and return them home after the SEP stack has returned. The SEP stage is responsible for moving the Cislunar Habitat (50t) from a NRO starting orbit, transiting to and from a destination, and returning to the NRO orbit. A couple of different trajectory destination options have been identified that would be possible within the 300-400 day class range and are gathered in Table 7 below. The type 3 example presented in further detail in this paper is a round trip rendezvous and landing trajectory to the asteroid 2000 SG344.

Table 7. Excursion Mission TYPE 3 Examples

\begin{tabular}{|l|l|}
\hline \multicolumn{1}{|c|}{$\begin{array}{c}\text { Mission } \\
\text { Name/Target }\end{array}$} & \multicolumn{1}{|c|}{ Description } \\
\hline \hline $\begin{array}{l}\text { Asteroid Surface } \\
\text { Exploration }\end{array}$ & $\begin{array}{l}\text { Rendezvous and orbit an asteroid. Land } \\
\text { human astronauts on its surface. } \\
\text { Approximately 30 days spent at the } \\
\text { asteroid. }\end{array}$ \\
\hline $\begin{array}{l}\text { Earth Resonant } \\
\text { Orbit }\end{array}$ & $\begin{array}{l}\text { Rendezvous with a body in a resonant } \\
\text { orbit with the Earth. Asteroid 3753 } \\
\text { Cruithne, which is in orbit about the sun } \\
\text { and in a 1:1 resonant orbit with the Earth, } \\
\text { could serve as a potential long duration } \\
\text { target for a human mission. Asteroid 2010 } \\
\text { TK7, classified as an Earth Trojan, which } \\
\text { precedes Earth in its orbit, could also serve }\end{array}$ \\
\hline
\end{tabular}

as a potential long duration mission target.

\section{SG344 Round Trip Excursion Concept Summary}

The Type 3 trajectory concept presented in this section is a low thrust round trip to rendezvous with the asteroid 2000 SG344. Previous studies have examined the use of electric propulsion as an enabling technology for human asteroid rendezvous missions. [7] The details of the trajectory are shown in Figure 7 below. The crew are delivered to rendezvous with the SEP/Habitat stack on an Orion but the Orion does not stay with the stack for the round trip mission. Rather, an additional Orion (uncrewed) is assumed to be launched to retrieve the crew once they return from the asteroid round trip mission. The SEP stack, consisting of the SEP stage (8t dry mass) and habitat (50t), depart from the NRO and perform a round trip mission to rendezvous with asteroid 2000 SG344. The details of the departure from the NRO are shown in the lower right box closeup in Figure 8. The total round trip mission time is 394 days, including a 30-day stay time at the asteroid. Activities at the asteroid are notional at this time, but could include surface operations. The SEP stage performs low thrust maneuvers upon return from the asteroid to return the SEP/Habitat stack to the NRO about the moon. Once the stack has returned, the second Orion is launched on an SLS to retrieve the crew and return them to Earth. The entire round trip mission requires the $150 \mathrm{~kW}$ SEP stage, operating at a $90 \%$ duty cycle and using a high thrust mode of operation to perform a total delta V of $2351 \mathrm{~m} / \mathrm{s}$, using $7.38 \mathrm{t}$ of Xe. This total delta V translates to 249 days of total thrusting on-time by the magnetically shielded Hall thrusters. A conceptual view of asteroid surface operations during this trajectory is shown in Figure 9.

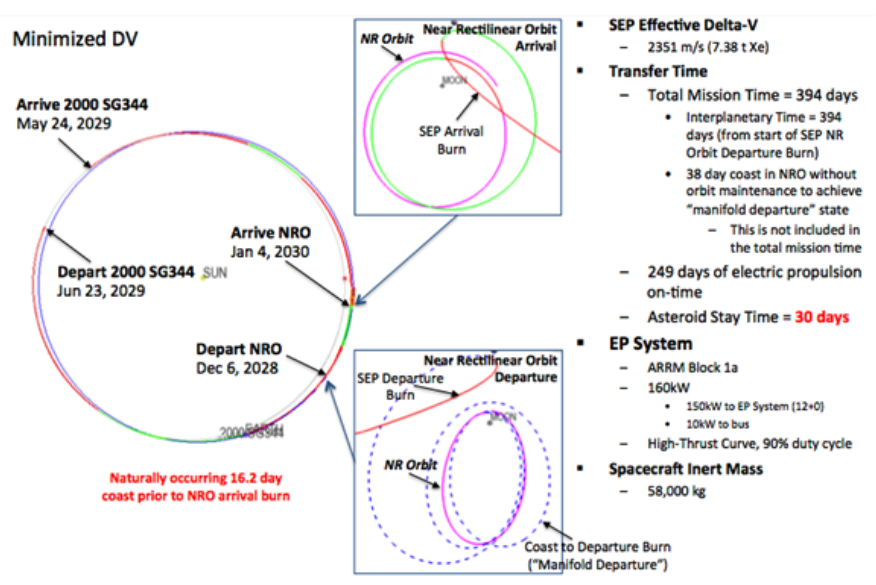

Figure 8: Conceptual Round trip Type 3 mission to asteroid SG344 


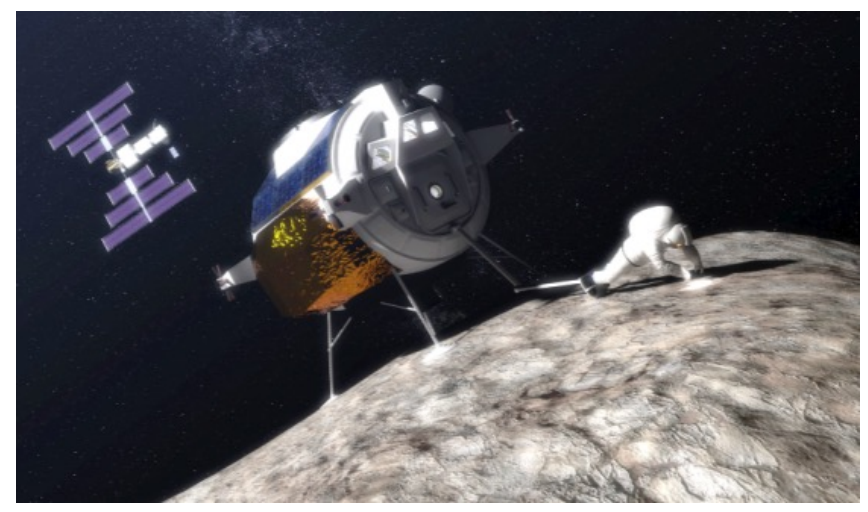

Figure 9: Conceptual View of Surface Operations on Asteroid SG344

\section{SUMMARY AND CONCLUSIONS}

Potential candidates for excursion concepts during the Proving Ground are being assessed based on assumed capabilities related to launch, in-space propulsion, and habitation elements. These trajectory concepts are gathered in terms of total mission length, and devised to each be longer in duration and further from earth than the previous concept type. It is thought that this would provide a feed forward path of increasingly more complicated and challenging concepts leading to eventual human missions beyond cislunar space and to Mars by proving out both technology and the ability to live and carry out missions farther and farther from Earth. Of the ten excursion trajectory destination concepts identified, five have been examined in more detailed analysis and are captured in this paper. Each class of trajectory extends the reach of human exploration progressively farther from planet Earth. For these excursion concepts, the following table gathers the maximum distance to the Earth. The distances are expressed as equivalent lunar distances from the Earth. The trajectory types captured in Table 8 are representative of the distances achievable given the mission durations of the three excursion mission categories. For each type, the progressively farther distance from Earth traveled by the astronauts sets a new distance record for human exploration.

\begin{tabular}{|c|c|c|c|}
\hline $\begin{array}{c}\text { Trajectory } \\
\text { Type }\end{array}$ & $\begin{array}{c}\text { Total } \\
\text { Delta V } \\
(\mathbf{m} / \mathbf{s})\end{array}$ & $\begin{array}{c}\text { Total Xe } \\
\text { (kg) }\end{array}$ & $\begin{array}{c}\text { Max Distance } \\
\text { To Earth } \\
\text { (lunar } \\
\text { distances) }\end{array}$ \\
\hline \hline TYPE 1 & TBD & $<2000$ & $\sim 1.7$ \\
\hline TYPE 2 & $\sim 500$ & $\sim 2000$ & $\sim 4.3$ \\
\hline TYPE 3 & $\sim 2700$ & $\sim 8800$ & $\sim 29.2$ \\
\hline
\end{tabular}

Table 8: Excursion Concept Summary

All of the conceptual analysis presented in this paper assumes that the same single SEP stage performs all three of the excursions, and that the SEP Stage repositions the stack and performs stationkeeping maneuvers both using SEP and using onboard RCS in-between missions as needed. The missions could be one after another sequentally in time with each subsequent trajectory farther and more complicated than the one previous, but there is no assumption as to the order. Initially, although the ARV concept allows for it, there is no expectation of refueling of the SEP stage unless after further analysis, it is determined that more than the $16 \mathrm{t}$ of Xe capacity is required for the full set of missions, including margin and station keeping in between the excursion missions. While analysis is open on the repositioning and station keeping needs, the propellant required to perform the three notional excursion class concepts explored in more detail here is well under the $16 \mathrm{t}$ payload capacity of the SEP stage.

\section{ACKNOWLEDGEMENTS}

The authors thank their management and technical support at NASA GRC, JPL and NASA JSC. Special thanks to the leadership of the Solar Electric Propulsion Technology Demonstration Mission (SEP TDM) at NASA GRC Michael Barrett and David Irimies and the ARRM Program Manager Brian Muirhead for their support and leadership in all things SEP. 


\section{REFERENCES}

[1] Brophy, John R., Brian Muirhead, "Near-Earth Asteroid Retrieval Mission (ARM) Study," IEPC-2013-82, Presented at the 33rd International Electric Propulsion Conference, Washington, DC, October 6 - 10, 2013.

[2] Percy, Thomas K., Melissa McGuire, and Tara Polsgrove. "In-space transportation for NASA's Evolvable Mars Campaign." AIAA Space. Vol. 2105. 2015.

[3] Landau, D. and Strange, N., "Human Exploration of NearEarth Asteroids via Solar Electric Propulsion," AAS-11102, 2011.

[4] Brophy, J.R., et al., "300-kW Solar Electric Propulsion System Configuration for Human Exploration of NearEarth Asteroids," AIAA-2011-5514, $47^{\text {th }}$ AIAA/ASME/SAE/ASEE Joint Propulsion Conference \& Exhibit, 21 July - 03 August 2011, San Diego, CA.

[5] Kamhawi, H., Huang, W., Haag, T., Yim, J., Chang, L., Clayman, L., Herman, D., Shastry, R., Thomas, R., Verhey, T., Griffith, C., Myers, J., Williams, G., Mikellides, I., Hofer, R., Polk, J., and Goebel, D., "Overview of the Development of the Solar Electric Propulsion Technology Demonstration Mission 12.5-kW Hall Thruster," GRC-E-DAA-TN16633, 50th AIAA/ASME/SAE/ASEE Joint Propulsion Conference, Cleveland, OH, July 28-30, 2014.

[6] Gates, M., Mazanek, D., Muirhead, B., Stich, S., Naasz, B., Chodas, P., McDonald, M., Reuter, J., "NASA's Asteroid Redirect Mission Concept Development Summary," 2015 IEEE Aerospace Conference, Big Sky, MT, Mar. 7-14, 2015.

[7] Mercer, C. R., Oleson, S. R., Pencil, E. J., Piszczor, M. F., Mason, L. S., Bury, K. M., Manzella, D. H., Kerslake, T. W., Hojnicki, J. S., and Brophy, J. P., "Benefits of Power and Propulsion Technology for a Piloted Electric Vehicle to an Asteroid," Space 2011 Conference and Exposition, AIAA, Long Beach, CA, Sept. 27-29, 2011.

[8] Lopez, Pedro, Mark A. McDonald, Jose M. Caram, Heather D. Hinkel, Jonathan T. Bowie, Paul A. Abell, Bret G. Drake, Roland M. Martinez, Paul W. Chodas, Kurt Hack, Daniel D. Masanek, "Extensibility of human asteroid mission to Mars and other destinations." Space Ops 13th International Conference on Space Operations. 2014.

\section{BIOGRAPHY}

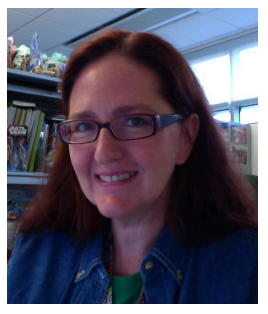

Melissa L. McGuire received her B.S. in Engineering Physics from John Carroll University in 1990, and an M.S. in Aerospace Engineering from The University of Cincinnati in 1992. She has been an aerospace engineer specializing in low thrust mission design with NASA Glenn Research Center for more than 20 years. She is currently the Mission Design Deputy for the Asteroid Redirect Robotic Mission (ARRM) which aims to retrieve a large boulder from an asteroid and place it in orbit of the Moon where it would be visited by astronauts as a precursor to human interplanetary missions.. Ms. McGuire has spent a great deal of her career performing mission design of both robotic and human missions to Mars and other targets of potential interest to exploration. Ms. McGuire is the deputy of and one of the founding members of the NASA GRC concurrent engineering team COMPASS and has spent much of the last 10 years running the system seat in the COMPASS concurrent design studies.

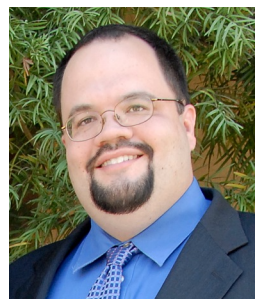

Nathan Strange has worked at NASA's Jet Propulsion Laboratory (JPL) since 2000, where he is currently a systems engineer for mission formulation in the Mission Concepts Section. He holds a M.S. in Aeronautics \& Astronautics from Purdue University and is pursuing a Ph.D. degree with Professor Jim Longuski in Astrodynamics and Space Applications. Nathan is the Mission Design lead for the Asteroid Redirection Robotic Mission concept which aims to retrieve a large boulder from an asteroid and place it in orbit of the Moon where it would be visited by astronauts as a precursor to human interplanetary missions. 


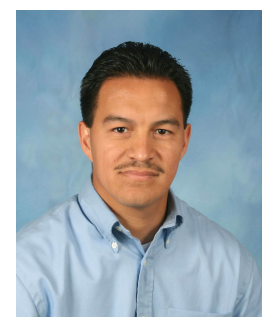

Pedro Lopez Jr. received his B.S. and M.S. in Mechanical Engineering from the University of Texas - Pan American in 2000 and 2003, respectively, and his Ph.D. in Mechanical Engineering from Rice University in 2014. He joined NASA JSC in 2007. He currently works as the Systems Engineering \& Integration (SE\&I) Lead for the Exploration Mission Planning Office (EMPO), and is currently the chair for the Future Capabilities Mission Design Team, which has been tasked with producing mission design documents for the Proving Ground. Prior to this, he worked as an SE\&I Lead for the Advanced Mission Development Group (AMDG), designing concepts for various potential mission scenarios including the Asteroid Redirect Crewed Mission (ARCM). He started his JSC career working as the Aerothermodynamics and Aerodynamics Technical Manager for the Space Shuttle Program SE\&I Office, while also serving as the Debris Integration Group (DIG) Deputy Manager. 
